\title{
FUNDAMENTAL STUDY OF AN ADAPTIVE EVACUATION GUIDE SIGN BY USING A DISCRETE ELEMENT METHOD-BASED SIMULATION
}

\author{
HIROSUKE HORII ${ }^{1}$, AKIHITO ITO ${ }^{2}$, NOBUTAKA TSUJIUCHI ${ }^{2}$, \\ TAKAHIRO FUKUDA ${ }^{2} \&$ YUSUKE KASAHARA ${ }^{2}$ \\ ${ }^{1}$ Kokushikan University, Japan \\ ${ }^{2}$ Doshisha University, Japan
}

\begin{abstract}
In this study, an adaptive evacuation guide sign is proposed, and a fundamental evaluation is performed by using a discrete element method (DEM)-based simulation. When a disaster occurs in a large, closed space that has many emergency exits, such as a building or an underground area, having an evacuation route guide to an emergency exit that avoids intensive congestion of evacuees is important. The adaptive evacuation guide sign monitors the situations of the disaster and the evacuation which changes frequently and controls the direction of evacuation. A simulation model is constructed by using a DEM-based simulation which introduces pseudo-spring and pseudo-radius to interactions among discrete elements for representing evacuees' behaviour. The pseudo-spring and the pseudo-radius are representing the personal space of evacuees and they affect interaction among evacuees during evacuation. At a fundamental evaluation, a limited area that has six emergency exits with three adaptive evacuation guide signs is modelled for evaluating efficiency of the guide sign.

Keywords: crowd behaviour simulation, evacuation simulation, discrete element method.
\end{abstract}

\section{INTRODUCTION}

When constructing a large architecture such as a building or an underground area is planned, evacuation plan is pre-examined to respond to disaster by investigating efficiency of an evacuation route or safety of a floor plan. But pre-examined evacuation plan is not enough to respond to the disaster, since the situations on evacuation route are changing dynamically such as blocking by obstacles or congesting by concentration of evacuees. In this study, we propose an adaptive evacuation guide sign which monitors situations of the disaster and the evacuation situations and controls the direction of evacuation dynamically.

A numerical simulation is applied to evaluate proposed system, since examination at actual large architecture is difficult. Investigation of occurrence mechanisms of panic and congestion at evacuation studied by Helbing et al. was one of the early studies of numerical simulation for analysing evacuation behaviour [1]. Since then, various computational approaches such as cellular automata or the lattice gas model have been investigated and applied to planning and evaluating actual evacuation plans such as evacuating at high-rise building [2] or optimizing a vessel layout [3].

Though the discrete element method (DEM) [4] has been mainly used in the field of geotechnical engineering or structural engineering, it has been extended for analysing human crowd behaviour by introducing human behavioural factors so far [5]. In this study, a DEMbased simulation is applied since the features of the DEM is appropriate for our investigation. The features of the DEM are: (a) solving and tracking position of each discrete element and (b) enabling quantitative evaluation of force transfer among discrete elements.

Firstly, simulation model by the DEM and introduced human behavioural factors are described. Then the system and the algorithm of proposed adaptive evacuation guide sign are described. Finally computational results are discussed. 


\section{SIMULATION MODEL}

Evacuation simulation model is constructed by using an extended DEM which introduced a pseudo-spring and a pseudo-radius. The pseudo-spring and the pseudo-radius represent personal space of each evacuee.

\subsection{Discrete element method}

In order to grasp complicated situation at evacuation quantitatively, a DEM-based simulation is employed. The DEM represents each evacuee as a discrete element, and then behaviour of each evacuee is observed as a movement of the element. Force transfer among evacuees in contact is represented by spring and dashpot at contact point shown in Fig. 1. Position of each element at every moment is solved and tracked by an independent equation of motion for each element. The equation of motion of $\mathrm{p}$-th element which constitutes a crowd of evacuees is represented as follows:

$$
\begin{aligned}
& m_{p} \ddot{x}_{p}(t)=f_{p}^{x}(t), \\
& m_{p} \ddot{y}_{p}(t)=f_{p}^{y}(t) .
\end{aligned}
$$

Here, $m_{p}, x_{p}$ and $y_{p}$ represent mass, displacement of $\mathrm{x}$ and $\mathrm{y}$ direction of the $\mathrm{p}$-th element. $f_{p}^{x}$ and $f_{p}^{y}$ represent resultant force of $\mathrm{x}$ and $\mathrm{y}$ direction affecting to the $\mathrm{p}$-th element respectively. The resultant force consists of resistant force of elastic spring of elastic coefficient $k$, resistant force of viscous spring of damping coefficient $c$ and individual's thrust force. The individual's thrust force is defined as force which receives until reaching a target walking velocity.

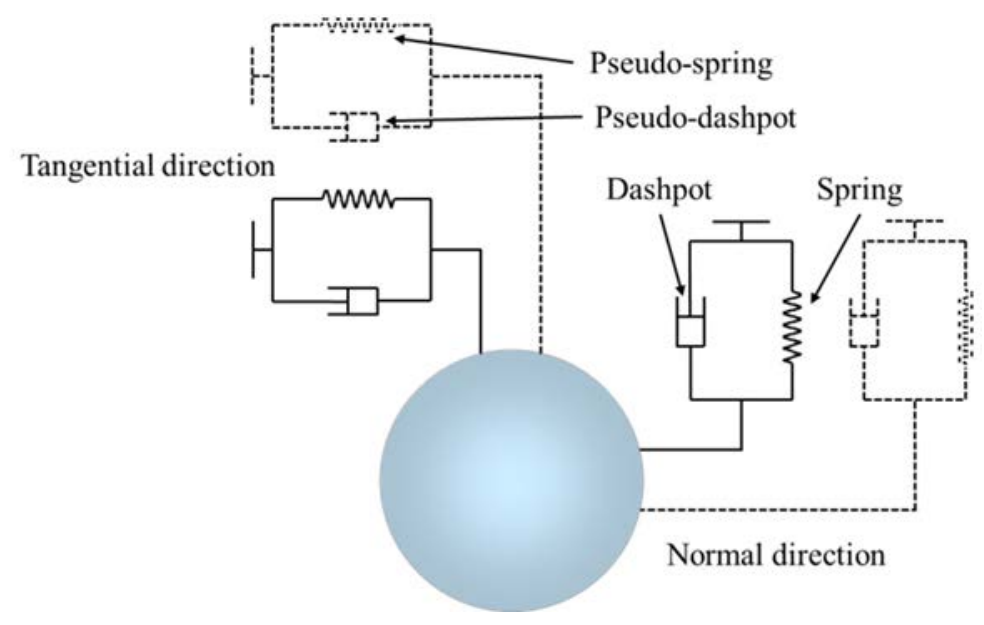

Figure 1: Force transfer among evacuees in a DEM.

\subsection{Introducing of pseudo-spring and pseudo-radius}

In this study, a pseudo-spring and a pseudo-radius shown in Fig. 2 are introduced for representing personal space which is the distance that a person likes to keep among other people. Before physical contact, a person will try to avoid an obstacle object and keep a 
certain distance psychologically. The pseudo-radius represents the psychological distance and is set to $0.8 \mathrm{~m}$ in this study. That is the spring represents physical reaction and the pseudospring represents psychological reaction. A viewing angle represents a person's viewing range and an expression area represents the activation area of the psychological avoidance.

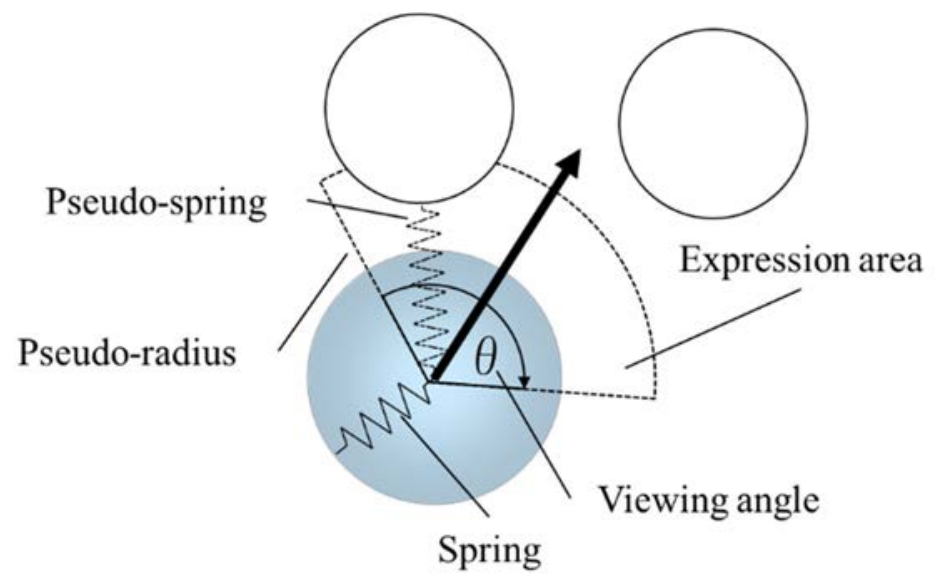

Figure 2: Pseudo-spring and pseudo-radius.

\section{ADAPTIVE EVACUATION GUIDE SIGN}

\subsection{Adaptive evacuation guide algorithm}

In this study, we propose an adaptive evacuation guide sign to evacuate smoothly. Though standard evacuation guide sign guides an evacuation direction according to a certain predetermined plan and the evacuation direction is set static, situations on the evacuation route are changing dynamically, such as blocking by obstacles or congesting by concentration of evacuees. The adaptive evacuation guide sign switches the evacuation direction dynamically with observing the situation. Fig. 3 shows an example of switching the evacuation direction. Firstly, the adaptive guide sign indicates a predetermined direction to evacuees as shown in Fig. 3(a). When congestion occurs at an emergency exit as shown in Fig. 3(b), the sign switches to an appropriate direction, the opposite direction here.

The adaptive evacuation guide sign proposing in this study observes the situations and reflects on switching of direction indication. The algorithm sets a certain threshold for the number of evacuees on evacuation routes and switches the directions to prevent the congestions when exceeding the threshold.

\subsection{Recognition area of adaptive evacuation guide sign}

In this study, recognition area of the adaptive evacuation guide sign is set on crossroads as shown in Fig. 4. Evacuees start evacuation at initial position and when they enter the recognition area, they recognize the guide sign and move to the indicated direction. The recognize rate of the guide sign is set to $100 \%$ here and the evacuees obey the direction. 

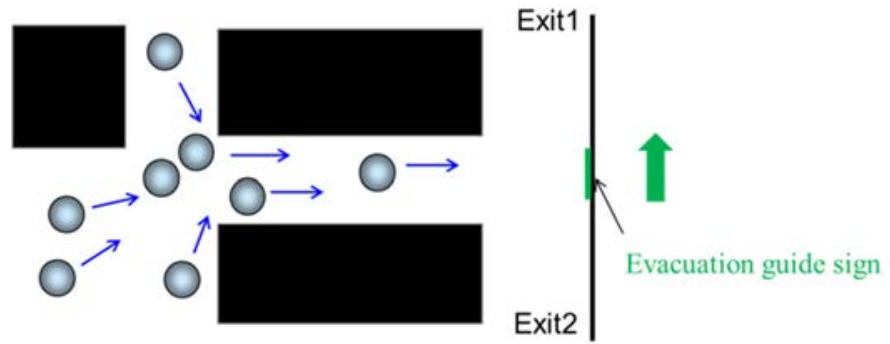

(a)
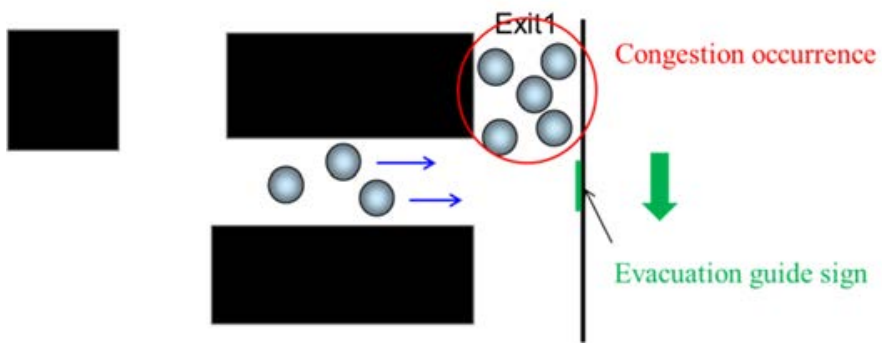

(b)

Figure 3: An example of the switching of evacuation direction indication. (a) Indication of predetermined direction at initial condition; and (b) Switching to the opposite direction when congestion occurred.

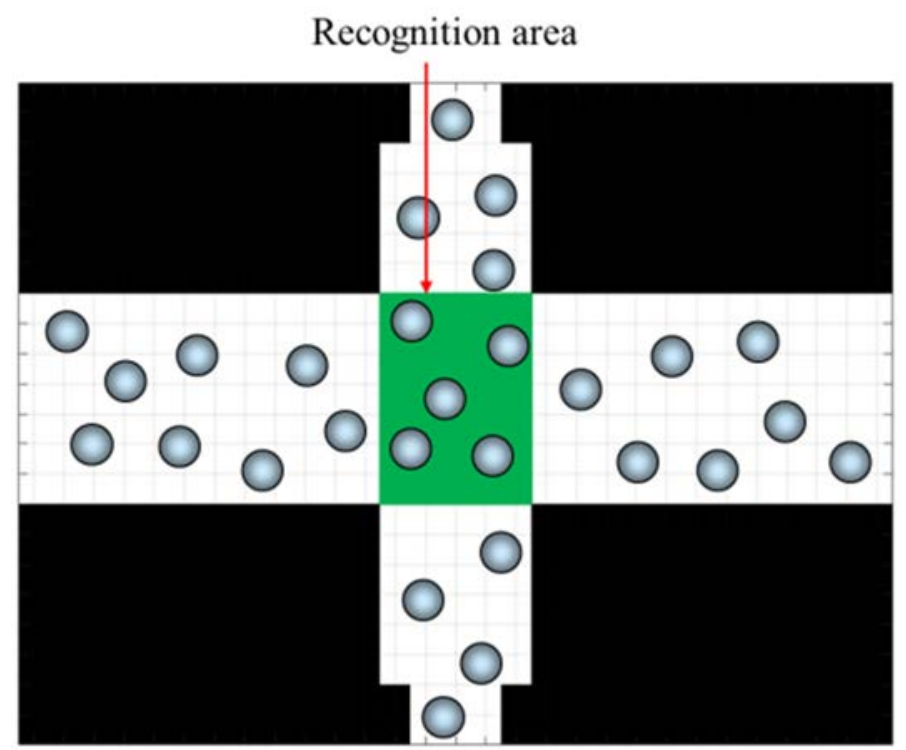

Figure 4: Recognition area of an adaptive evacuation guide sign. 


\subsection{Investigations of criteria for detecting congestion for switching evacuation direction}

For implementing the algorithm described the above, we investigate the threshold of the number of evacuees on evacuation routes as a criterion for detecting congestion for switching the evacuation direction. The investigations are carried out by using a crossroad as shown in Fig. 5. Range of the main passageway of the horizontal direction is $13 \mathrm{~m}$ distance and $3 \mathrm{~m}$ width. Range of the sub-passageway to exits is $10 \mathrm{~m}$ distance and $2.5 \mathrm{~m}$ width, and the exits are $1.3 \mathrm{~m}$ width. 75 evacuees are set at initial position on the passageway. The investigations are carried out by changing the threshold in the range of 1 to 30 and comparing with a fixed direction case as a standard evacuation guide sign. The other parameters are shown in Table 1.

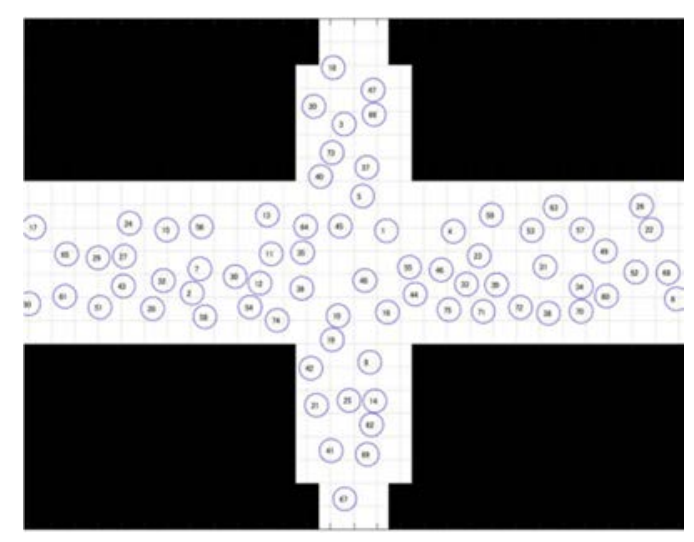

Figure 5: Schematic of passageway for investigation.

Table 1: Parameters of simulation.

\begin{tabular}{|l|c|}
\hline Radius of particle (evacuee): $\mathrm{r}(\mathrm{m})$ & $2.15 \mathrm{e}-1$ \\
\hline Pseudo-radius: $\mathrm{Ah}(\mathrm{m})$ & $8.00 \mathrm{e}-1$ \\
\hline Mass: $\mathrm{m}(\mathrm{kg})$ & $6.0 \mathrm{e} 1$ \\
\hline Moving velocity: $\mathrm{v}(\mathrm{m} / \mathrm{s})$ & $0.8-1.8$ \\
\hline Individual's thrust force: $\mathrm{Fg}(\mathrm{N})$ & $1.74 \mathrm{e} 2$ \\
\hline Time step: $\Delta \mathrm{t}(\mathrm{s})$ & $1.0 \mathrm{e}-2$ \\
\hline Viewing angle: $\theta($ deg.) & 100 \\
\hline Spring constant $\left(\right.$ Normal, Tangential): $\mathrm{k}^{\mathrm{u}}, \mathrm{k}^{\mathrm{v}}(\mathrm{N} / \mathrm{m})$ & $9.18 \mathrm{e} 3,4.09 \mathrm{e} 2$ \\
\hline Damping constant $\left(\right.$ Normal, Tangential): $\mathrm{c}^{\mathrm{u}}, \mathrm{c}^{\mathrm{v}}(\mathrm{Ns} / \mathrm{m})$ & $1.10 \mathrm{e} 3,2.47 \mathrm{e} 2$ \\
\hline Pseudo-spring constant $\left(\right.$ Normal, Tangential): $\mathrm{k}^{\prime \mathbf{u}}, \mathrm{k}^{\prime \mathrm{v}}(\mathrm{N} / \mathrm{m})$ & $4.50 \mathrm{e} 2,2.71 \mathrm{e} 0$ \\
\hline Pseudo-damping constant $\left(\right.$ Normal, Tangential): $\mathrm{c}^{\prime \mathrm{u}}, \mathrm{c}^{\prime \mathrm{v}}(\mathrm{Ns} / \mathrm{m})$ & $3.39 \mathrm{e} 0,2.63 \mathrm{e} 1$ \\
\hline
\end{tabular}

Ten trials of each condition are carried out by changing the initial position of the evacuees. Fig. 6 shows the mean and the standard deviation of completion time of evacuation at 10 trials of each condition. The mean and the standard deviation at standard guide sign are shown on the left side. According to the computational results, 16 of the thresholds is the most efficient value for preventing congestion and shorten the evacuation time. Thus we employ 16 of the thresholds for evacuation simulation at below section. 


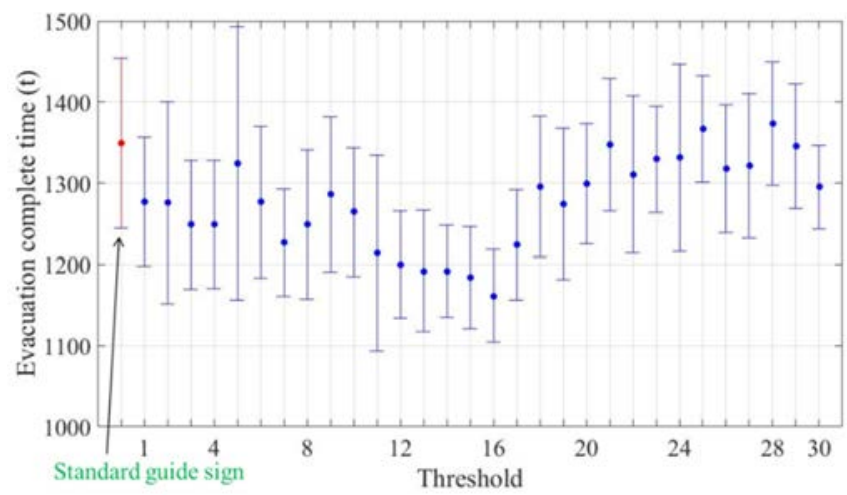

Figure 6: Mean and standard deviation of completion time of evacuation.

\section{EVACUATION SIMULATION}

In this section, evacuation simulations by using the adaptive evacuation guide sign described the above are carried out for investigating extension to massively evacuation simulation.

\subsection{Simulation conditions}

Schematic of passageway of the simulation is shown in Fig. 7. Main passageway of $28 \mathrm{~m}$ distance and $3 \mathrm{~m}$ width is set along with horizontal direction. Three sub-passageways of $10 \mathrm{~m}$ distance and $2.5 \mathrm{~m}$ width are set crossing to the main passageway and connecting to exits of $1.3 \mathrm{~m}$ width. Initial positions of 250 evacuees are set on the passageway at random as shown in Fig. 8. The other parameters are set as same as the above section on Table 1. The evacuation simulations are carried out with two guide policies. The two guide policies are (A) fixed evacuation direction of the standard guide sign and (B) variable evacuation direction of the adaptive guide sign proposed in this study. In policy A, each evacuee goes to the nearest exit. In policy B, each evacuee obeys the direction indicated by the adaptive guide sign. If the number of evacuees near an exit is less than the threshold, then the adaptive guide sign indicates both directions and every evacuee goes to the nearest exit respectively. And if the number exceeds the threshold, then the guide sign indicates to the opposite direction or more vacant direction.

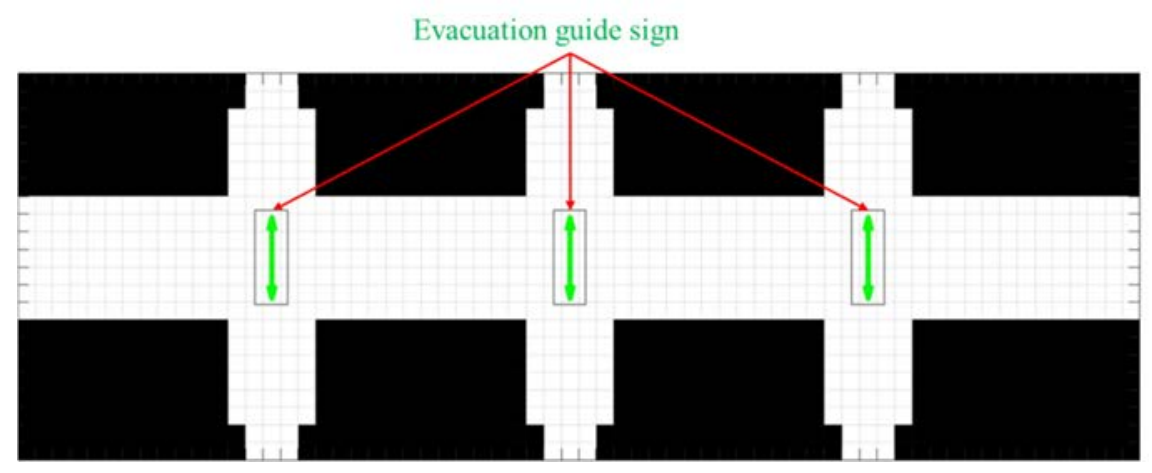

Figure 7: Schematic of passageway of evacuation simulation. 


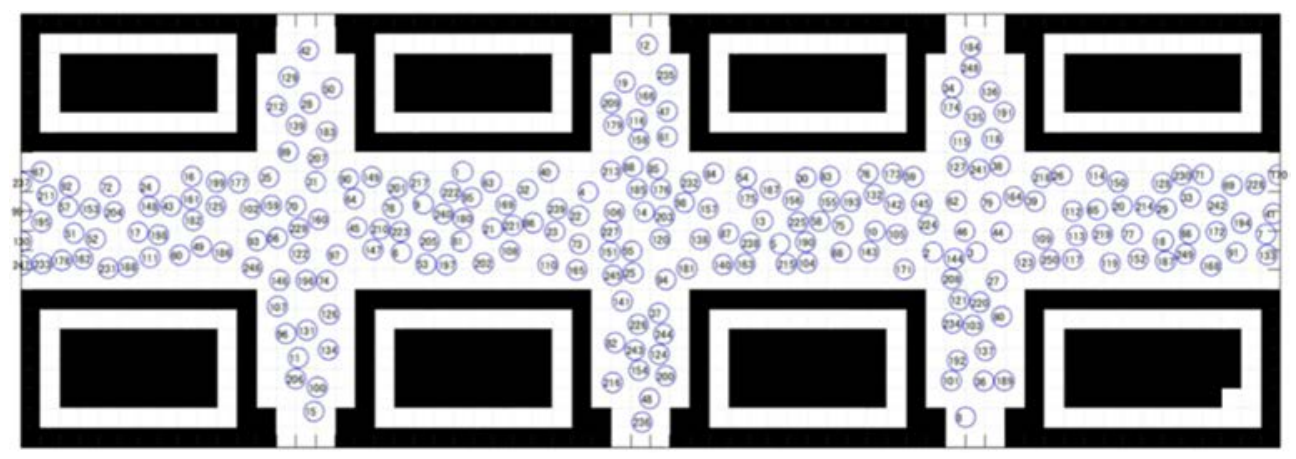

Figure 8: Initial position of evacuees.

\subsection{Results and discussion}

Completion time of evacuation at each exit is shown in Table 2 and Fig. 9 shows an evacuation situation at time of $\mathrm{t}=6 \mathrm{sec}$. When we focus on evacuees on places circled in red, congestions were occurred at sub-passageways near exits by biasing to one side at policy $\mathrm{A}$ as shown in Fig. 9(a). On the other hand, the biases were disappeared at policy B as shown in Fig. 9(b), and the completion time of evacuation was shortened. However a problem has remained at the policy B. Though congestion was disappeared at centre sub-passageway, congestions were still occurred at both left and right sub-passageways. In this case, each evacuation guide sign observes the situation around itself and assigns evacuees to upper and lower exits in charge of guide independently. But if the guide signs share their observed overall situations and guide to another vacant exits in cooperate such as evacuating from left and right sub-passageways to centre sub-passageway, optimum evacuation guide will be realized. And further investigation and improvement of this point is necessary for applying this system in massively area.

Table 2: Completion time of evacuation at each exit.

\begin{tabular}{|c|c|c|c|c|}
\hline & \multicolumn{2}{|c|}{ Policy A } & \multicolumn{2}{|c|}{ Policy B } \\
\hline Exit name & $\begin{array}{l}\text { Completion } \\
\text { time (sec.) }\end{array}$ & $\begin{array}{l}\text { Difference } \\
\text { (sec.) }\end{array}$ & $\begin{array}{l}\text { Completion } \\
\text { time (sec.) }\end{array}$ & $\begin{array}{l}\text { Difference } \\
\text { (sec.) }\end{array}$ \\
\hline $\begin{array}{c}\text { Exit 1 } \\
\text { (upper left) }\end{array}$ & 10.83 & \multirow{2}{*}{3.54} & 12.12 & \multirow{2}{*}{0.25} \\
\hline $\begin{array}{c}\text { Exit } 2 \\
\text { (lower left) }\end{array}$ & 14.37 & & 11.87 & \\
\hline $\begin{array}{c}\text { Exit } 3 \\
\text { (upper centre) }\end{array}$ & 7.31 & \multirow{2}{*}{3.52} & 9.36 & \multirow{2}{*}{0.7} \\
\hline $\begin{array}{c}\text { Exit } 4 \\
\text { (lower centre) }\end{array}$ & 10.83 & & 10.06 & \\
\hline $\begin{array}{c}\text { Exit } 5 \\
\text { (upper right) } \\
\end{array}$ & 10.33 & \multirow{2}{*}{2.44} & 11.21 & \multirow{2}{*}{0.36} \\
\hline $\begin{array}{c}\text { Exit } 6 \\
\text { (lower right) }\end{array}$ & 12.77 & & 11.57 & \\
\hline
\end{tabular}




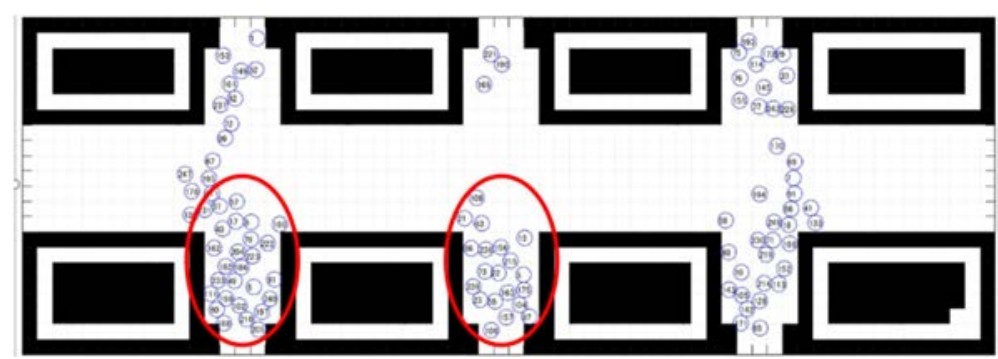

(a)

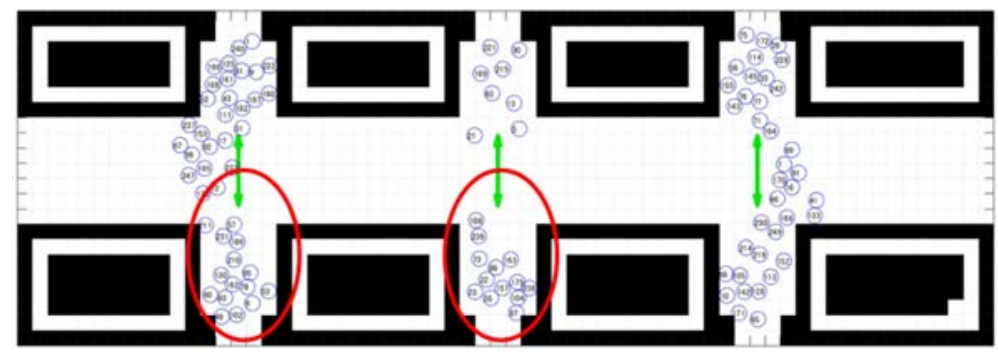

(b)

Figure 9: Evacuation situation at time of $\mathrm{t}=6$ sec. (a) Policy A; and (b) Policy B.

\section{CONCLUDING SUMMARY}

In this study, an adaptive evacuation guide sign was proposed, and a fundamental evaluation was performed by using a DEM-based simulation. Firstly, the number of evacuees on evacuation routes as a criterion for detecting congestion for switching the evacuation direction was investigated. And then, a fundamental investigation was carried out by using a limited area model. As a result, although the effectiveness of the adaptive evacuation guide sign was shown, in addition to that, the necessity of cooperation among them was understood at applying to massively structures in future.

\section{ACKNOWLEDGEMENT}

This work was partly supported by a grant from the Suzuki Foundation.

\section{REFERENCES}

[1] Helbing, D., Farkas, I. \& Vicsek, T., Simulating dynamical features of escape panic. Nature, 407, pp. 487-490, 2000.

[2] Kinsey, M.J., Galea, E.R. \& Lawrence, P.J., Investigating the use of elevators for highrise building evacuation through computer simulation. Proceedings of Human Behaviour in Fire Symposium 2009, pp. 85-96, 2009.

[3] Deere, S.J., Galea, E.R. \& Lawrence, P.J., Optimising vessel layout using human factors simulation. Proceedings of Pedestrian and Evacuation Dynamics 2008, pp 597-603, 2010.

[4] Cundall, P.A. \& Strack, O.D.L., A discrete numerical model for granular assembles. Geotechnique, 29, pp. 47-65, 1979.

[5] Lim, S.W.H. \& Lim, E.W.C., Human Evacuation Modeling. Discrete Event Simulations - Development and Applications, IntechOpen, pp. 135-142, 2012. 